\title{
Research on the Formation of Network Ethical Consciousness of College Students
}

\author{
Zhuojing FU \\ Marxism Institute \\ Shanghai University of Medicine and Health Sciences \\ ShangHai, China
}

\author{
Lei SUN \\ President Office \\ Chinaoriental Investment Management Co., Ltd. \\ ShangHai, China
}

\begin{abstract}
With the advent of the network times, cyberspace has become another mainstream space on which people rely for survival. The maintenance of fairness and justice in cyberspace requires people living in the network to assume corresponding responsibilities with good intentions and self-discipline. Different moral rules have conflicts in cyberspace, which need correct network ethics to solve. This paper chooses the representative moral conflict problem in cyberspace and seeks to solve it by the core content of network ethics. As the backbone of cyberspace, the cultivation of college students' network ethics will be more conducive to the protection of college students' rights in cyberspace, as well as the social legal and security barrier in cyberspace. The cultivation of college students' network ethical consciousness is closely related to the characteristics of the network itself. Only through the mutual communication of service network technology and morality can the moral hazard of network space be controlled through network ethics.
\end{abstract}

Keywords-network ethics; network speech freedom; network privacy protection; professional ethics

\section{INTRODUCTION}

With the development of technology, smartphones and mobile networks are widely used. People's work and life are increasingly dependent on the Internet. The boundary between cyberspace and real space is becoming more and more blurred. Network reconstructs connection, relationship and trust. It brings about the remolding of social structure and relationship model. The continuous intersection of cyberspace and real space has profoundly affected people's way of life. The network stretches the dimension of space and time, which not only brings convenience and rapidity to people but also dramatically magnifies the moral and legal problems existing in the real space in the network. New structures require new rules, new ethics, and according to the physical architecture of cyberspace, many problems cannot be solved by law alone. There are still a lot of gaps in the existing network legislation, the construction of network ethics is of great significance.[1]

Network ethics is not only for technology, but also for every person and every organization in reality. Technology has a certain objectivity. Human subjective consciousness set rules to determine how technology for human service. Contemporary college students, as the backbone of cyberspace, are connected with the Internet every day from basic necessities of life, to study and practice, to employment and entrepreneurship. For them, whether the Internet is safe or dangerous, whether it is good or bad, whether it is a tool of entrepreneurship or a tool of fraud, actually all depend on everyone's understanding of the rules and inner understanding. The cultivation of college students' awareness of network ethics will help network space become a legal and safe barrier.

\section{CORE CONTENTS OF NETWORK ETHICS}

Many ethical problems in network society are transplanting from real society to network society. For example, social moral decline, credit crisis, trust crisis, these phenomena have entered the network society. In real society, people's behavior is basically under the supervision of others and the constraints of various moral norms, so the moral system and legal system can be well maintained and implemented. However, in the cyberspace, behaviors are characterized by "digitization" or "virtualization". The supervision system in real society loses its function in the cyberspace. Online morality can only be sustained by personal inner beliefs. In addition, new problems in cyberspace, maintained by moral norms in real society, may lead to various moral and behavioral conflicts. Therefore, it is necessary to cultivate the correct network ethics consciousness to solve the moral contradictions in the network space.

The development of the Internet has gone through three levels: the age of information network, the age of social network and the age of the Internet of things. Each level has its own characteristics. Each level does not represent the end of the previous level, but four levels are presented in cyberspace at the same time. The network subverts people's way of study, life and thinking in a digital and intelligent way. While reshaping the political, economic, cultural, legal and other social systems in line with the characteristics of cyberspace, it needs to reflect on the advantages and disadvantages of network technology to human civilization from an interdisciplinary perspective. The existing legal framework cannot cover the problems in cyberspace, which means that the maintenance of fairness and justice in cyberspace requires people living on the Internet to take corresponding responsibilities with good intentions and self-discipline. However, different moral rules are in conflict in cyberspace. Just as the development of network technology brings convenience to people, it also brings corresponding problems. The existence of network ethics is the mutual communication of service network technology and morality to control the moral hazard of network space. 
Network ethics includes network technology ethics and network ecological environment ethics. Network technology ethics mainly refers to the practical subject of research, development, management and application of basic network technology. The principle and systematic philosophical thinking deal with the relationship between technology subject and technology service object, technology subject and society shutdown, and the relationship between technology subject and technology subject. The network technology ethics takes the technical manager as the main body. The main body of network ecological environment ethics should include all individuals and organizations that use, utilize and manage the network in the network space. Network with the development of information network technology ethics and ecological ethics are intertwined. The scholar thinks almost all network problems and widely use of information and communication technology has more or less contact. Richard mason (1986) proposed "ownership, access rights, privacy and accuracy" as the core of the network ethics.[2]

\section{NETWORK ARCHITECTURE -- THE PATH OF NETWORK ETHICS INFLUENCING NETWORK GOVERNANCE}

The structure of network space has its particularity. According to yoza benkler, the network is divided into physical architecture layer, code layer and content layer. Lawrence reisger also adopts this hierarchical concept. Code is law. He argues. And problems that arise in cyberspace can be solved by design, either by an information worker or by an engineer using technology, which increases the responsibility of a technician. John perry barlow's classic 1996 book, the declaration of the independence of cyberspace, is a model of liberal Internet governance, calling on governments around the world to fully open up cyberspace so that all Internet users can govern the Internet. Although this theory has been questioned by other scholars, it can also be seen that cyberspace is different from real space. The architecture of cyberspace determines the influence path of network ethics on network governance from the bottom of the network. The ethics of network technology plays a greater role in the layer of network code, while the ethics of network ecological environment stays in the layer of network content.

\section{CONTENTS OF NETWORK ETHICS EDUCATION FOR COLLEGE STUDENTS}

\section{A. Freedom of online expression and risk control of online public opinions}

In recent years, with the gradual increase of network users, network public opinion has in fact been gradually guiding the direction of social hot events. As the network real-name system, network digital account application, network virtual space gradually fade out, turn into offline online version of the space. In such an environment, simple network public opinion as risk control in the virtual space has been unable to adapt to reality. So the research on citizen network freedom of expression gradually raises, mainly divides into how to use rules to control and network ethics. American scholar Lawrence Lessig (1999) once proposed that the network is jointly controlled by commercial forces and government forces, and the content of the network can be regulated by law, market, technical framework and social norms. On this basis, Richard a. pinello (2003) proposed the ultimate administrator model of cyberspace, that is, the core moral value should guide and control the way in which law, market, technical framework and social norms play their normative role, but it is not clear how the core moral value integrates into the thinking of network code writers. He adjusted the normative principle of morality into four principles: the principle of autonomy, the principle of no harm, the principle of advantage and the principle of justice. Michael J.Quinn (2015) proposed that freedom of speech is not absolute freedom. Protecting the freedom of speech on the Internet can promote the public to take place in the public domain, thus promoting the government to be responsible to the public. However, freedom of speech is not an absolute right, and it should be balanced with social and public interests. Those people who abuse this right should be punished. In general, American scholar of network freedom of speech with political freedom as the core, they think that when the government and enterprise network platform, countries can affect network through code freedom of speech. The citizen's network freedom of speech has been weakened. So the country not only keeps net neutrality, but also network legislation protects citizens freedom of speech. Chinese scholars have studied this aspect from the initial protection of online speech freedom to the current discussion of the boundary of online speech freedom. Other scholars, such as Chen chunzhu (2013), Yang kai zheng (2015) and wang jui (2017), hold that online freedom of speech is related to personal privacy and public interests and should be regulated by legislation to ensure a balanced relationship among the three. Scholars qi aimin (2003), Chen daoying (2012) and Mei xiaying (2017) believe that online freedom of speech is not limited to the game between citizens and the government. After the rise of wemedia platforms, we-media platforms play an increasingly important role in influencing and controlling online freedom of speech.[3]He qinhua (2018) believes that the right to access the Internet is the guarantee and expression of freedom of speech. Social right is the guarantee of freedom of speech on the Internet, both of which belong to the political rights of citizens, freedom of speech and freedom of expression. The friction between freedom of speech and privacy is the most frequent, but privacy is the boundary and guarantee of freedom of speech. Freedom of speech is central to these four rights. It is not only related to the other three network rights, but also to the basic political, economic and cultural human rights of citizens.[4]Tang xiaoyan (2006) believes that the basic principle of western ethics is individualism, while the moral principle of Chinese network society should explain the principle of freedom and autonomy under the guidance of the principle of collectivism. College students are active in cyberspace, especially the backbone of online social media. They are active in voicing opinions on hot issues on the Internet and dare to present the views of young people. From the perspective of students, freedom of expression on the Internet is the embodiment of guaranteeing the freedom of speech of citizens. However, the virtuality of network space and the rapidity of network communication lead to the formation of hot spots of network public opinion and the huge influence and social risk in real society. Therefore, it is the best 
way to reduce social risks to control the spread of false information and conduct benign guidance of network public opinion from the perspective of administrators such as schools and governments. It is difficult to balance the interests of all parties in the existing legal framework. Selecting typical cases to carry out network ethics education for college students is the best entry point.

\section{B. Network information collection and personal privacy protection}

The superposition of big data technology and network technology announces that mankind has entered the era of big data. Although big data technology has existed for a long time, with the development of the Internet (especially the mobile Internet) and digital storage, big data technology has greater leeway to play. Information collection, processing, exchange, dissemination and utilization have become an important part of human activities and created great wealth. Information resources have become trading objects with rich forms and huge scale. Especially when information is combined with the network, the network provides a convenient carrier for the flow of information. The information industry grows rapidly, and information can create huge commercial value, which has shown property value in economic activities. At the moment, the importance of personal information protection has never been seen before.

At present, network information collection can be divided into two categories: first, the original data related to personal information can be obtained through APP; secondly, the original data obtained are reapplied to business by background algorithms. When these data are aggregated, a database is formed. This database may be the individual information of a certain kind of group, or the information collection of a certain kind of group. The database contains a large amount of information. From the perspective of business activities, merchants collect this information and establish personal data files in order to better serve consumers and provide more accurate services.

However, from the perspective of individuals, even if merchants protect their personal information, such an algorithm will do more harm to the data subject than the original data collection behavior. The network develops the personal privacy space from tangible physical space to an invisible virtual space. As a virtual space, the network space is not closed, and the personal privacy protection in the network space forms a new type of privacy -- information privacy. This privacy is different from the previous emphasis on the privacy of personal life not to be disturbed, more emphasis on personal control of information. American scholar a. Michael frum gold thinks, "the rapid development of information collecting technology brings to the informational privacy damage is unprecedented, monitoring technology would violate the privacy of others, but the degree of monitoring technology into modern life as well as the individual information is processed in the database or we cannot imagine. If the state does not adopt new laws or social norms to strengthen the protection of privacy, then the privacy of individuals in modern society will be lost.
The basic concept of the network is to achieve maximum information sharing, which is in essential conflict with the privacy requirements and control requirements of individuals for their own information. In this way, the confidentiality of personal information, control and network information sharing conflict, and will be more prominent with the popularity of the mobile network.[5]

Although college students live on campus, the campus wall cannot become the boundary of virtual network space. In recent years, network security incidents caused by information leakage of college students emerge in endlessly. In particular, college students are active in online social platforms. From the perspective of college students, these platforms are platforms supported by information technology for communication and maintaining personal relationships. The interest of social platforms is to obtain as accurate personal information as possible from users, and on this basis, target targeted advertisements to maintain the operation of the platform. Especially on social platforms, the emergence of network user groups leads to college students often actively expose their personal information or passively expose their interests and hobbies through user groups. Therefore, how to correctly understand the legitimacy of network information collection and the importance of personal information privacy protection has become another important proposition to cultivate college students' awareness of network ethics. To deal with this contradiction correctly is helpful for college students to build their awareness of network security and protect their privacy. It is also helpful for college students to enhance their legal awareness and not infringe on others' right to network information.

\section{Network technology and professional ethics constraints}

Network technology is a kind of science and technology. The development of network technology promotes the development of social economy and provides people with all kinds of convenient services. However, technology is mainly a tool of human beings, and how to effectively play the role of technology requires human beings to make rules. This is the meaning expressed in the traditional culture of our country. In the early pre-qin period, different schools of thought such as Confucianism, Taoism, legalism, guan zi and mohism interpreted this idea from different perspectives. The ethical thought of "using the tao to drive the art" is rooted in the technical practice in ancient China. It emphasizes the role of ethics and morality in guiding and regulating the technical practice, so as to prevent technical activities from causing negative effects on people's social life. In the network technology changes with each passing day today, such guiding ideology is still playing an important role. For example, while network technology facilitates data storage, there is also the phenomenon of hackers stealing data; while facilitating people's information search, there is also the phenomenon of human flesh search. While accelerating the transmission of information, there is also the phenomenon of rumor propagation; at the same time of providing work and life service for people in an all-round way, the phenomenon of Internet addiction also exists. To prevent the above negative phenomena, the self-discipline of Internet users is more effective than law. Self-discipline is a kind of internal power. 
Network users form a sense of conscience, justice, responsibility and honor in the process of using the network, and it is an internal self-consciousness of being responsible for themselves, others and society. This internal consciousness plays a decisive role in the value orientation and behavior norms of network users. Self-discipline consciousness of the form is in the network users under the premise of free will, give full play to their autonomy, stimulate the internal need of morals and moral emotion, through the guidance of value, gradually will Internet ethical principles, specification as the network users own inner law or code of conduct, to their own internal needs, and in practice, through repeated exercise, raise their moral ability, form the correct values and their own lofty moral character, and to regulate their own behavior. With the increasingly close relationship between network technology and social life, it is imperative to strengthen the cultivation of college students' awareness of network ethics. Systematic education of moral education is one of the most direct ways to cultivate college students' awareness of network ethics.[6]

In college education, professional ethics education is an important content of ideological and political courses, which is of great significance when combined with network ethics education. There is no doubt that the development of all walks of life and the Internet are inextricably linked. Network ethics is not just for engineers at the network code layer, but also for web users at the content layer. For undergraduate education, it should pay attention to the cultivation of college students' network knowledge. Both theoretical knowledge and practical operation of education, including the network activities of professional law might affect the analysis. And the analysis of internalization, the form of network activity of a kind of forecasting ability and to avoid risk, safeguards social public interests. Therefore, to cultivate college students' awareness of network ethics and guide them with self-discipline and responsibility will help them maintain a certain respect for the network in their work in the future, so as to form moral selfdiscipline and apply them to professional practice.[7]

\section{CONCLUSION}

The problem of cyberspace is complicated, among which there are different moral contradictions. In the absence of some legal parts, some contradictions need to be solved by network ethics. For example, how to prevent the formation of network [8] public opinion risk under the protection of individual freedom of speech on the Internet? How to protect the privacy of personal information when using personal information. How to use the Internet with professional ethics. For college students, cultivating correct awareness of network ethics and making them understand relevant contents of network technology ethics and network ecological environment ethics will not only help protect their individual rights, but also play an important role in their future career development. What needs to be paid attention to is that network infrastructure needs to be adopted when carrying out network ethics education. Network ethics cannot be discussed without the basic structure of network. To help students understand how to properly harness network technology and make it available to humans. Understanding the problems existing in the network can be solved through correct ethical consciousness, and finally make the network an ideal space for people.

\section{ACKNOWLEDGMENT}

We thank for the support of Shanghai school party construction research project (No.DJYJ-2019-C57).Fu Zhuojing, the author, wishes to thank Sun Lei for his help.

\section{REFERENCES}

[1] Yang Rongjun. Personal dignity protection: kernel network civilization and the construction of network ethics value, moral and civilization, 2017.5, pp.100 -109.(In Chinese)

[2] Zang Xiangyu, Tian Zhijian. Guidance and control on ethical issues of network culture security, Journal of Nantong University. Social science edition, 2016.3, pp.151-156.(In Chinese).

[3] Mei Xiaying, Yang Xiaona. The formation and normative path of network power of we-media platform -- based on the analysis of the impact on network freedom of speech, Hubei law, 2017.1, pp.36-47.(In Chinese)

[4] He Qinhua, Wang Jing. Network security is the core of network rights protection, 2018.7, pp.2-20.(In Chinese)

[5] He Yunfeng. Network information responsibility and network ethics education, journal of east China normal university (philosophy and social science edition), 2008.2, pp.108-114.(In Chinese)

[6] Xu Yuzhen, Xiao Chengjun. Internet speech anomy and its multi-center governance, contemporary law, 2016.3, pp.52-59.(In Chinese)

[7] Yang Jindan. Research on the formation mechanism of network ethics teachers for college students, exploration of higher education, 2019.1, pp.118-123.(In Chinese). 